\title{
Effects of Pleasant or Unpleasant Feedback Messages on the Learning of Timing
}

\author{
Tadao Ishikura \\ Sports Science and Health, Doshisha University, Kyoto, Japan \\ Email: tishikur@mail.doshisha.ac.jp
}

How to cite this paper: Ishikura, T. (2017). Effects of Pleasant or Unpleasant Feedback Messages on the Learning of Timing. $A d$ vances in Physical Education, 7, 1-9. https://doi.org/10.4236/ape.2017.71001

Received: November 7, 2016

Accepted: December 26, 2016

Published: December 29, 2016

Copyright (C) 2017 by author and Scientific Research Publishing Inc. This work is licensed under the Creative Commons Attribution International License (CC BY 4.0).

http://creativecommons.org/licenses/by/4.0/

\begin{abstract}
We investigated the effects of pleasurable and unpleasurable messages on the learning of timing using a ten-key pressing task. The messages affected the participants' emotions and provided them with knowledge of the results (KR). A total of 42 university students participated in this experiment. They were divided into three groups: the pleasurable message group (PMG), the unpleasurable message group (UMG), and the control group (CG). Participants were required to 1) press " 2 ", " 4 ", " 8 ", and " 6 " in order on the ten-key pad, 2) finish within $1100 \mathrm{~ms}$ of pressing "2", and 3) press with relative time intervals of $22.2 \%, 44.4 \%$, and $33.3 \%$. All groups were provided with the following KR after every practice trial: total time and relative time intervals. Participants in the PMG and UMG groups were provided with pleasurable or unpleasurable messages, respectively, if their total times were within $\pm 5 \%$ of the range, or when any of their time intervals fell outside of $\pm 10 \%$ of the range. Three pretest trials, 30 practice trials, and three posttest trials were performed on Day 1. Three retention trials and 3 transfer trials were performed on Day 2. The transfer trials total time was $1800 \mathrm{~ms}$, and that of the relative time interval was the same as on Day 1 . The results indicate that although all groups learned the timing task, the UMG had higher variable and root mean square errors on the transfer test compared to the PMG and CG. These results suggest that unpleasurable messages are disadvantageous for learning stable timing during the ten-key pressing task because unpleasurable emotions may negatively affect cognitive processing.
\end{abstract}

\section{Keywords}

Feedback Messages, Pleasure, Displeasure, Emotion, Learning of Timing Movements

\section{Introduction}

The pleasurable or unpleasurable messages provided by teachers and coaches 
likely affect students' or players' emotions, motivation to complete activities, learning strategies, and memory for learned skills during physical education classes and sports activities. For example, it has been reported that emotion influences the type of information processing used in decision-making, expectations of the results, and past memories (Schwarz, 2000). In addition, emotion and cognition are correlated with decision-making and motivation to complete activities of daily life (Izard, 2011).

It is generally known that pleasurable emotions promote decision-making and problem-solving, as long as there is social activity and a thinking process, and the subject is interesting and important (Isen, 1999). It has been reported that humiliation, insults, blame, and threats from elementary schoolteachers lead to unpleasurable emotions in children, while eulogies, praise, and encouragement lead to pleasurable emotions (Aliyev, Karakus, \& Ulus, 2013). Ithas also been reported that the supportive actions of junior high school teachers, such as those supporting a student's strategies and encouraging social constructs that support students, improved the students' motivational and management abilities (Wallace, Sung, \& Williams, 2014).

Sugawara, Tanaka, Okazaki, Watanabe, and Sasato (2012) examined the effects of praise on motor learning using a serial finger-tapping task. The results indicated that the group that was praised for their performance had significantly better performance than did either the group that watched other participants receive praise or the group that was not praised when the participants suddenly performed the learned serial finger-tapping movement. However, there were no significant differences among the three groups when the participants performed the task using a new serial random-order movement. They thus concluded that motor skill improvements due to praise are observed when praise is provided while the task is not being performed (off-line monitoring) rather than during the task (on-line monitoring).

Kris and Shalini (2012) reported that creativity-contingent rewards are effective if the participants are provided with pleasurable feedback accidentally while they are learning, and that this feedback leads to performance that is more creative. On the other hand, performance-contingent or completion-contingent rewards have slightly negative effects on creative performance. Hooyman, Wulf, and Lewhwaite (2014) examined the effects of three types of instruction using the cricket bowling action task: instruction supporting the participant's independence during the learned behavior, instruction controlling the learned behavior, and in-between instruction. The results indicated that the selection rate is highest for instruction that supports the participant's independence during the learned behavior, and that this type of instruction improved confidence, reduced the necessity of dealing with unpleasurable emotions, and had positive effects on kinesthetic memory in comparison to instruction controlling the learned behavior. These reports indicate that the pleasurable words of others, remuneration, and supportive social constructs positively affect the participant's attitude, motivation, and efficacy during the task and greatly improve performance. 
Unpleasurable emotions reportedly narrow the range of attention during cognitive tasks and decrease the thought-action repertoire (Frederickson \& Branigan, 2005). Ogawa, Masaki, Yamazaki, and Sommer (2001) have reported that participants who were verbally admonished had smaller decreases in their errorrelated negativity potentials and reduced performance monitoring compared to a control group. In other words, unpleasurable emotions are likely disadvantageous in terms of motor skill learning in comparison to pleasurable emotions. Based on these reports, we may assume that pleasurable emotions during motor learning facilitate learning compared to unpleasurable emotions. We thus examined the effects of pleasurable or unpleasurable messages on motor skill learning using a timing movement task.

\section{Methods}

\subsection{Participants}

The participants were 42 university students ( 25 men and 17 women) with a mean age of 20.1 years (standard deviation $[\mathrm{SD}]=1.3$ years). Each participant's dominant hand was determined using the Chapman's dominant hand test (Chapman \& Chapman, 1987). All participants were right-handed, and none had previously experienced the task.

This experiment was conducted after approval was obtained from the Doshisha University Ethics Committee for Scientific Research Involving Human Subjects.

\subsection{Task and Apparatus}

The task is illustrated in Figure 1. The participant was seated in front of a 19-in.

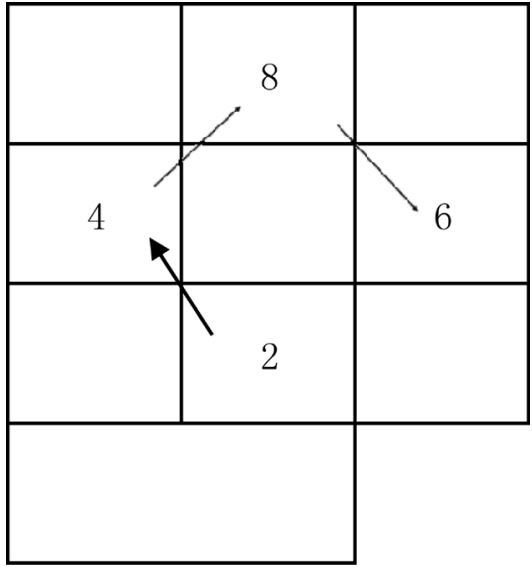

Figure 1. Timing movement task. All participants were required to press the keys as follows: 1) press 2, 4, 8, and 6 in order using the right index finger; 2 ) press the " 6 " key on the ten-key keyboard within 1,100 ms after initiating the sequence by pressing the " 2 " key; and 3 ) press the keys with relative time intervals of $22.2 \%, 44.4 \%$, and $33.3 \%$ between the " 2 " key and the " 4 " key, the " 4 " key and the " 8 " key, and the " 8 " key and the " 6 " key, respectively. 
monitor (Mitsubishi RDT195LM) that had been positioned on a desk. Each participant was required to press a ten-key pad on a computer keyboard using their right hand in the following order: $2,4,8$, and 6 . The goal was to complete these four sub-movements in $1100 \mathrm{~ms}$, and to maintain relative time intervals of $22.2 \%, 44.4 \%$, and $33.3 \%$ between the pressing of 2 and 4,4 and 8 , and 8 and 6 , respectively.

\subsection{Procedures}

The participants provided written, informed consent and received $\backslash 1000$ cash as compensation for their cooperation. The experiment was conducted with each participant individually.

Figure 2 shows the experimental procedure. After the task and the procedure were explained, each participant performed a pretest consisting of three trials with no knowledge of results (KR).

The participants then performed a practice phase consisting of 30 trials. Each participant was assigned, by sex, to one of three groups: the pleasurable message group (PMG), the unpleasurable message group (UMG), and the control group (CG). Performance time was measured from the moment the "2" key was pressed to the moment the " 6 " key was pressed, and a relative time interval was calculated. All participants were provided with KR on the monitor after every trial, which consisted of their performance time and a related time interval. The PMG and UMG were provided with a pleasurable or unpleasurable message, respectively, if the participant's total time was $\pm 5 \%$ (from $1045 \mathrm{~ms}$ to $1155 \mathrm{~ms}$ ) outside the range, or if one of the time intervals was outside $\pm 10 \%$ of the range ("2" key - "4" key: from $12.2 \%$ to $32.2 \%$, "4" key - " 8 " key: from $34.4 \%$ to $54.4 \%$, "8" key - "6" key: from $23.3 \%$ to $43.3 \%)$.

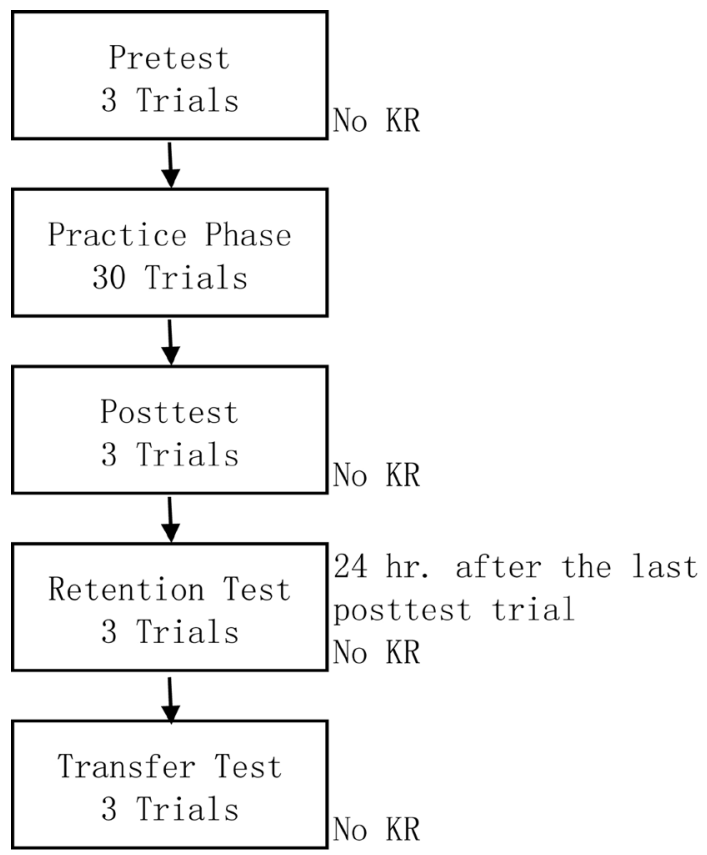

Figure 2. Experimental procedure. 
Table 1 shows the pleasurable and unpleasurable messages used in this experiment (Ishikura \& Fujimoto, 2014). These messages were provided by replaying audio files with voices from male and female university students who were actors in the university's drama program.

A posttest consisting of three trials with no KR was conducted 15 seconds after the practice phase. A retention test consisting of three trials and a transfer test consisting of three trials were performed with no KR on the next day. During the transfer tests, although the participants were asked to press the same keys in the same order with the same relative time intervals as in the original task,

Table 1. Pleasurable and unpleasurable messages used in this experiment.

\begin{tabular}{|c|c|c|c|}
\hline \multicolumn{2}{|c|}{ Pleasure } & \multicolumn{2}{|c|}{ Unpleasure } \\
\hline "Lets keep it up." & “There's next time." & "Not good enough." & "Go home." \\
\hline "You Improved." & $\begin{array}{c}\text { "You become } \\
\text { stronger repeating } \\
\text { failure." }\end{array}$ & $\begin{array}{c}\text { "Its normal to able to } \\
\text { do that." }\end{array}$ & "You're not good." \\
\hline "You're doing it." & $\begin{array}{l}\text { “There's things that } \\
\text { you realize by failing." }\end{array}$ & $\begin{array}{l}\text { “That wasn't from } \\
\text { your strength.” }\end{array}$ & $\begin{array}{l}\text { "You must } \\
\text { be stupid." }\end{array}$ \\
\hline $\begin{array}{l}\text { "Its coming up } \\
\text { quite well.” }\end{array}$ & "You can do it." & $\begin{array}{l}\text { "Other people can do } \\
\text { better." }\end{array}$ & $\begin{array}{c}\text { "You can't } \\
\text { do even this." }\end{array}$ \\
\hline "You did well." & "Failure is needed." & $\begin{array}{l}\text { "Your skill is not up } \\
\text { to par." }\end{array}$ & "Just as I thought." \\
\hline $\begin{array}{l}\text { "Your effort has } \\
\text { paid off." }\end{array}$ & $\begin{array}{l}\text { "Lets try hard } \\
\text { together." }\end{array}$ & $\begin{array}{l}\text { "You're thinking } \\
\text { to easy." }\end{array}$ & $\begin{array}{l}\text { "You're not } \\
\text { getting it." }\end{array}$ \\
\hline "That was good." & "Don't give up." & “That was lucky.” & $\begin{array}{l}\text { "You have no } \\
\text { motivation." }\end{array}$ \\
\hline $\begin{array}{c}\text { "You never let me } \\
\text { down." }\end{array}$ & "It starts from here." & $\begin{array}{l}\text { "It doesn't mean } \\
\text { anything if you can't } \\
\text { do it in a match." }\end{array}$ & $\begin{array}{l}\text { "Anyone can do } \\
\text { that." }\end{array}$ \\
\hline "You've got talent." & “A little bit more." & $\begin{array}{l}\text { “It took you a } \\
\text { long time." }\end{array}$ & $\begin{array}{l}\text { "There's no next } \\
\text { time." }\end{array}$ \\
\hline “That was cool." & "One more time." & $\begin{array}{l}\text { "Anyone could } \\
\text { do that." }\end{array}$ & $\begin{array}{c}\text { "I was expecting } \\
\text { failure." }\end{array}$ \\
\hline "You’re very good." & $\begin{array}{l}\text { "You will be able to } \\
\text { do it next time." }\end{array}$ & "Not bad." & $\begin{array}{l}\text { "Your not meant } \\
\text { for this." }\end{array}$ \\
\hline “That was superb." & $\begin{array}{l}\text { "There's more you } \\
\text { can do." }\end{array}$ & "I’ve had enough." & "It's over." \\
\hline “Good work/job.” & $\begin{array}{l}\text { “Sometimes you're } \\
\text { just out of form." }\end{array}$ & $\begin{array}{l}\text { “There's no chance } \\
\text { you can do it." }\end{array}$ & $\begin{array}{l}\text { "Your not going to } \\
\text { get any better." }\end{array}$ \\
\hline $\begin{array}{l}\text { "It was a result of } \\
\text { your training." }\end{array}$ & $\begin{array}{l}\text { "Your getting much } \\
\text { better." }\end{array}$ & "Don't play with me." & "It's impossible." \\
\hline $\begin{array}{l}\text { "Lets try hard to the } \\
\text { next level." }\end{array}$ & $\begin{array}{l}\text { "I have a good } \\
\text { feeling." }\end{array}$ & $\begin{array}{l}\text { "What were you } \\
\text { doing until now?" }\end{array}$ & $\begin{array}{l}\text { "Not enough } \\
\text { practice." }\end{array}$ \\
\hline "You can do better." & "Nice Try." & "You should quit." & "That was normal." \\
\hline $\begin{array}{l}\text { "Try hard next time } \\
\text { too." }\end{array}$ & & $\begin{array}{c}\text { "Are you putting in } \\
\text { any effort?" }\end{array}$ & \\
\hline
\end{tabular}


they were also asked to press the "6" key $1800 \mathrm{~ms}$ after pressing the "2" key. When a participant pressed the wrong key, it was considered to be an error. The participant then resumed the task by pressing the " 2 " key.

E-Prime 2.0 Professional (Psychology Software Tools Inc.) psychological experimental software was used to control the experimental protocol and to measure the movement times.

\subsection{Dependent Variables}

The time interval in ms between pressing the " 2 " key and pressing the " 6 " key was recorded. Data from the pretest, the posttest, the retention test, and the transfer test are summarized for the three trial blocks. Absolute error (AE) and variable error (VE)were used to evaluate performance in terms of total time, and root mean square error (RMSE) was used to evaluate performance in terms of relative time intervals. These measures of error were the dependent variables. To estimate the number of times the participants in the PMG and the UMG received messages regarding timing errors, the number of deviations from the time range during the practice phase was recorded.

\subsection{Analysis}

One-way analyses of variance (ANOVAs) were used to assess differences in the three variables (AE, VE, and RMSE) on the pretest and the numbers of messages received by participants in the PMG and the UMG during the practice phase. A three-way ( 3 [group: PMG, UMG, CG] $\times 2$ [sex: male, female] $\times 3$ [test: pretest, posttest, retention test]) repeated measures ANOVA was used to evaluate performance acquisition. A two-way ( 3 [group] $\times 2$ [sex]) ANOVA was used to evaluate learning during the transfer test. All significant effects are reported using $p<0.05$ as the significance level. Effect sizes are reported as $\eta^{2}$, and statistical power is reported as $\phi$. Post hoc comparisons of the means were performed using the Bonferroni technique. IBM SPSS Statistics Version 24 (IBM, Inc.) statistical software was used for all statistical analyses.

\section{Results}

Table 2 shows the means and standard deviations of AE, VE, and RMSE for each test. There were no significant differences among the three groups for $\mathrm{AE}$, VE, and RMSE, as determined by a one-way ANOVA for pretest performance (see Table 2).

\subsection{Acquisition}

AE, VE, and RMSE for the three groups were computed. A significant effect of Test was observed for $\operatorname{AE}\left(F_{2,72}=13.80, \mathrm{p}=0.01, \eta^{2}=0.28, \phi=1.00\right)$, VE $\left(F_{2,72}=\right.$ $\left.8.55, \mathrm{p}=0.01, \eta^{2}=0.19, \phi=0.96\right)$, and RMSE $\left(F_{2,72}=15.49, \mathrm{p}=0.01, \eta^{2}=0.30\right.$, $\phi=1.00)$. Post hoc comparisons of AE, VE, and RMSE indicated that the pretest values were higher than the posttest and retention test values, and that there were no differences in the posttest and the retention test. There were no main 
Table 2. Group means and standard deviations for absolute error, variable error, and root mean square error on the pretest, posttest, retention test, and transfer test.

\begin{tabular}{|c|c|c|c|c|c|c|c|c|}
\hline \multirow{3}{*}{ Group } & \multicolumn{8}{|c|}{ Experimental Phase } \\
\hline & \multicolumn{2}{|c|}{ Pretest } & \multicolumn{2}{|c|}{ Posttest } & \multicolumn{2}{|c|}{ Retention Test } & \multicolumn{2}{|c|}{ Transfer Test } \\
\hline & $M$ & $S D$ & $M$ & $S D$ & $M$ & $S D$ & $M$ & $S D$ \\
\hline \multicolumn{9}{|c|}{ Absolute Error on each test } \\
\hline PMG & 514.81 & 708.01 & 91.43 & 89.5 & 206.10 & 156.36 & 423.14 & 203.94 \\
\hline UMG & 669.12 & 822.59 & 173.74 & 99.22 & 181.74 & 173.04 & 361.29 & 158.03 \\
\hline CG & 463.29 & 425.13 & 124.29 & 96.58 & 114.98 & 63.86 & 404.95 & 155.99 \\
\hline Total & 549.07 & 662.29 & 129.82 & 98.95 & 167.60 & 141.63 & & \\
\hline \multicolumn{9}{|c|}{ Variable Error on each test } \\
\hline PMG & 456.30 & 999.10 & 43.65 & 36.14 & 100.98 & 68.17 & 129.82 & 91.52 \\
\hline UMG & 271.40 & 199.04 & 80.49 & 50.83 & 87.54 & 66.70 & 223.08 & 127.33 \\
\hline CG & 251.10 & 348.55 & 73.43 & 75.87 & 71.43 & 50.26 & 112.55 & 63.68 \\
\hline Total & 326.27 & 613.45 & 65.86 & 57.62 & 86.65 & 61.92 & & \\
\hline \multicolumn{9}{|c|}{ Root Mean Square Error on each test } \\
\hline PMG & 0.17 & 0.10 & 0.08 & 0.02 & 0.09 & 0.04 & 0.11 & 0.05 \\
\hline UMG & 0.18 & 0.08 & 0.11 & 0.04 & 0.12 & 0.06 & 0.14 & 0.06 \\
\hline CG & 0.13 & 0.06 & 0.10 & 0.06 & 0.11 & 0.07 & 0.11 & 0.03 \\
\hline Total & 0.16 & 0.09 & 0.10 & 0.05 & 0.11 & 0.06 & & \\
\hline
\end{tabular}

Note-There were no significant differences or interactions in the pretest or the retention test in any of the variables between the groups. There were no significant differences in absolute error between the groups in the transfer test. PMG: pleasurable message group, UMG: unpleasurable message group, CG: control group.

effects of group or sex, and there were no significant interactions between the variables.

\subsection{Transfer Tests}

$\mathrm{AE}, \mathrm{VE}$, and RMSE for the three groups were computed for the transfer test (see Table 2). There was a main effect of Group for VE $\left(F_{2,36}=4.65, \mathrm{p}=0.02, \eta^{2}=\right.$ $0.21, \phi=0.75)$ and $\operatorname{RMSE}\left(F_{2,36}=3.23, \mathrm{p}=0.05, \eta^{2}=0.15, \phi=0.58\right)$. Post hoc comparisons of VE and RMSE indicated that the pretest values were higher than those of the posttest and the retention test, and that there were no differences in the posttest and the retention test. There was no significant main effect of sex, and there were no significant interactions for VE and RMSE. There were no significant effects of Group or Sex, nor any significant interactions for AE.

\subsection{Numbers of Messages}

There were no significant differences in the numbers of messages provided during the practice phase among the three groups. The mean of the number of messages provided was $28.7(\mathrm{SD}=1.8)$.

\section{Discussion}

The values for the posttest and the retention test, which took place on the day after the original task was practiced, decreased less than those of the pretest. We 
thus observed learning of the timing movement. However, on the transfer test, which took place on Day 2, the UMG had larger VE and RMSE than the PMG and the CG. We may thus conclude that listening to unpleasurable messages may lead to unstable task performance retention.

Frederickson and Branigan (2005) reported that unpleasurable emotions lead to a narrowing of the scope of attention during cognitive tasks and decrease the thought-action repertoire. It has been reported that participants receiving verbal admonitions have decreased error-related negativity potentials and reduced performance compared to control group participants (Ogawa, Masaki, Yamazaki, \& Sommer, 2011). In the central nervous system, the striatum, which is a basal nucleus in the brain that may include the amygdala, participates in the formation of memories of kinetic system sequences. Since the basal nuclei of the brain accelerate purposeful movements and control unnecessary movements, movement control may be affected if the amygdala is stimulated.

Since we did not observe differences between the groups for the original task, we may conclude that the messages had no influence on learning. However, we clearly show that participants who heard unpleasurable messages during the transfer task were more unstable than those in other groups. Therefore, our results may indicate that listening to unpleasurable messages leads to unstable performance in the transfer task in comparison to listening to pleasurable messages or to not listening to a message at all. This may be because the selection of memory information, performance monitoring, and amygdala stimulation in the central nervous system influences cognitive processing, which is needed to appropriately transfer the kinesthetic memory of the learned original task.

Future studies would require examinations of the effects of emotion-evoking messages on the central nervous system using functional magnetic resonance imaging. In addition, since the timing movement task was used as a learning task in this study, future studies should focus on other movement-constituting elements. These include the role of space during the performance of movements (e.g., throwing darts) or the need to adjust the force of a movement. It would thus be necessary to consider the influence of pleasurable or unpleasurable messages on the learning of movement.

\section{Acknowledgements}

The author would like to thank the students who participated in this study and the undergraduate research assistants who aided in the data collection process.

\section{Declaration of Conflicting Interests}

The author declare no potential conflicts of interest with respect to the research, authorship, and/or publication of this article.

\section{Funding}

This research was supported by JSPS KAKENHI Grant Number 26350734. 


\section{References}

Aliyev, R., Karakus, M., \& Ulus, H. (2013). Teachers' Verbal Cues That Cause Students to Feel Various Emotions. Anthropologist, 16, 263-272.

Chapman, L. J., \& Chapman, J. P. (1987). The Measurement of Handedness. Brain and Cognition, 6, 175-183. https://doi.org/10.1016/0278-2626(87)90118-7

Frederickson, B. L., \& Branigan, C. (2005). Pleasure Emotions Broaden the Scope of Attention and Thought-Action Repertories. Cognition and Emotion, 19, 313-332. https://doi.org/10.1080/02699930441000238

Hooyman, A., Wulf, G., \& Lewthwaite, R. (2014). Impacts of Autonomy-Supportive versus Controlling Instructional Language on Motor Learning. Human Movement Science, 36, 190-198. https://doi.org/10.1016/j.humov.2014.04.005

Isen, A. M. (1999). Chapter 25 Positive Affect. In T. Dalgleish, \& M. J. Power, (Eds.), Handbook of Cognition and Emotion (pp. 521-539). New Jersey: Wiley. https://doi.org/10.1002/0470013494.ch25

Ishikura, T., \& Fujimoto, A. (2014). Will Feedback Messages after Performance of an Activity Evoke Positive/Negative Emotion in Learners? Doshisha Journal of Health \& Sports Science, 6, 47-56. (In Japanese)

Izard, C. E. (2011). Forms and Functions of Emotions: Matters of Emotion-Cognition Interactions. Emotion Review, 3, 371-378. https://doi.org/10.1177/1754073911410737

Kris, B., \& Shalini, K. (2012). Rewards and Creative Performance: A Meta-Analytic Test of Theoretically Derived Hypotheses. Psychological Bulletin, 138, 809-830. https://doi.org/10.1037/a0027652

Ogawa, K., Masaki, H., Yamazaki, K., \& Sommer, W. (2011). The Influence of Emotions Due to Verbal Admonishment and Encouragement on Performance Monitoring. NeuroReport, 22, 313-318. https://doi.org/10.1097/WNR.0b013e328345bf42

Schwarz, N. (2000). Emotion, Cognition, and Decision Making. Cognition and Emotion, 14, 433-440. https://doi.org/10.1080/026999300402745

Sugawara, S. K., Tanaka, S., Okazaki, S., Watanabe, K., \& Sadato, N. (2012). Social Rewards Enhance Offline Improvements in Motor Skill. PLoS ONE, 7, e48174. https://doi.org/10.1371/journal.pone.0048174

Wallace, T. L., Sung, H. C., \& Williams, J. D. (2014). The Defining Features of Teacher Talk within Autonomy-Supportive Classroom Management. Teaching and Teacher Education, 42, 34-46. https://doi.org/10.1016/j.tate.2014.04.005 
Submit or recommend next manuscript to SCIRP and we will provide best service for you:

Accepting pre-submission inquiries through Email, Facebook, LinkedIn, Twitter, etc. A wide selection of journals (inclusive of 9 subjects, more than 200 journals)

Providing 24-hour high-quality service

User-friendly online submission system

Fair and swift peer-review system

Efficient typesetting and proofreading procedure

Display of the result of downloads and visits, as well as the number of cited articles Maximum dissemination of your research work

Submit your manuscript at: http://papersubmission.scirp.org/

Or contact ape@scirp.org 